\title{
PENGARUH ATTENUASI SINAR-X TERHADAP GREY VALUE COMPUTED RADIOGRAPHY
}

\section{ATTENUATION EFFECT OF X-RAY ON GREY VALUE COMPUTED RADIOGRAPHY}

\author{
Djoli Soembogo \\ Pusat Aplikasi Isotop dan Radiasi-BATAN, Jalan Lebak Bulus Raya No. 49, Jakarta 12440. \\ Email :
}

Diterima: 16 Oktober 2018, diperbaiki : 23 Oktober 2018, disetujui : 8 Nopember 2018

\begin{abstract}
ABSTRAK
PENGARUH ATTENUASI SINAR-X TERHADAP GREY VALUE COMPUTED RADIOGRA-PHY. Studi aplikasi radiografi digital dengan sinar- $X$ dan media Imaging Plate dengan pemindai Computed Radiogrphy. Radiografi ini menggunakan Imaging Plate blue (25 mikron) untuk mendapatkan kontras tinggi, kepekaan tinggi dan kualitas bayangan (image) yang baik karena butiran kristal halus. Tujuan radiografi digital menggunakan pemindai Computed Radiography adalah untuk mengetahui pengaruh ketebalan filter screen $\mathrm{Pb}$ terhadap grey value radiografi. Telah dilakukan pengujian radiografi menggunakan sinar- $X$ pada Ignition Coil dengan metoda ketebalan tunggal bayangan tunggal menggunakan media Imaging Plate blue dengan pemindai Computed Radiography dan sinar- $X$ dengan parameter pengamatan grey value radiografi. Waktu paparan sinar-X adalah 120 detik. dengan menggunakan tegangan tinggi $130 \mathrm{kV}$, arus $5 \mathrm{~mA}$, dan jarak sumber ke film (SFD) tegak lurus adalah $1200 \mathrm{~mm}$. Hasil pengujian radiografi digital dengan media Imaging Plate blue dengan pemindai Computed Radiography pada Ignition Coil dengan metoda ketebalan tunggal bayangan tunggal menghasilkan parameter grey value rerata 55429,24; 32759,32; 20616,99; 13122,75; 8825,85 pada ketebalan filter screen $\mathrm{Pb}$ (perisai) 0; 0,125 mm;0,25 mm;0,375 mm;0,5 mm. Semakin tebal filter screen $\mathrm{Pb}$ menghasilkan grey value yang semakin rendah.
\end{abstract}

Katakunci : Computed Radiography, filter screen $\mathrm{Pb}$, grey value.

\section{ABSTRACT}

ATTENUATION EFFECT OF X-RAY ON GREY VALUE COMPUTED RADIOGRAPHY. This study applies digital radiography using $X$-rays and uses Imaging Plate media with $a$ Computed Radiogrphy scanner. This radiography uses an Imaging Plate blue (25 microns) to get high contrast, high sensitivity and good image quality because of fine crystalline granules. The purpose of digital radiography using a Computed Radiography scanner is to determine the effect of the thickness of the screen $\mathrm{Pb}$ filter on the grey value of radiographic. Radiographic testing using $X$-rays on Ignition Coil was carried out using a single shadow thickness method using Imaging Plate blue media with Computed Radiography and X-ray scans with observation parameters of gray value radiography. X-ray exposure time is 120 seconds. by using a high voltage of $130 \mathrm{kV}$, a current of $5 \mathrm{~mA}$, and a perpendicular source to film (SFD) distance is 1200 $\mathrm{mm}$. The results of digital radiography testing with Imaging Plate blue media with a Computed Radiography scanner on Ignition Coil with a single shadow single thickness method resulted in a mean gray value parameter of 55429.24; 32759.32; 20616.99; 13122.75; 8825.85 in screen filter thickness $\mathrm{Pb}$ (shield) $0 ; 0.125 \mathrm{~mm} ; 0.25 \mathrm{~mm} ; 0.375 \mathrm{~mm} ; 0.5 \mathrm{~mm}$. The thicker the $\mathrm{Pb}$ screen filter produces the lower gray value.

Keyword : Computed Radiography, screen Pb filter, grey value. 


\section{PENDAHULUAN}

\section{Keterbatasan pengoperasian} tegangan tinggi mesin sinar- $\mathrm{X}$ dari pabrikan (yaitu minimal $130 \mathrm{kV}$ ), maka diperlukan reduksi tegangan tinggi dibawah 130 kV, sehingga didapatkan grey value radiografi yang sesuai untuk material uji. Pengurangan tegangan tinggi dibawah $130 \mathrm{kV}$ dilakukan menggunakan filter screen $\mathrm{Pb}$. Pengurangan tegangan tinggi ini setara dengan attenuasi energi sinar- $X$ yang akan berpengaruh pada reduksi grey value radiografi. Jika tidak dilakukan pengurangan tegangan tinggi, maka akan menghasilkan grey value radiografi sangat tinggi dan tidak dapat dibaca. Penelitian ini mengaplikasikan radiografi digital menggunakan sinar- $\mathrm{X}$, media Imaging Plate blue atau IP blue (perekam bayangan laten akibat radiasi sebagai pengganti film radiografi) dengan pemindai Computed Radiography dengan melihat pengaruh ketebalan filter screen $\mathrm{Pb}$. Penggunaan filter screen $\mathrm{Pb}$ bertujuan mengurangi (attenuasi) energi dari sinar- $X$ karena penggunaan tegangan tinggi sinar-X minimal $130 \mathrm{kV}$. Radiografi ini menggunakan Imaging Plate blue (25 mikron) untuk mendapatkan kontras tinggi, kepekaan tinggi dan kualitas bayangan (image) yang baik. Tujuan radiografi digital menggunakan media Imaging Plate blue adalah untuk mengetahui pengaruh ketebalan filter screen $\mathrm{Pb}$ terhadap tingkat grey value (tingkat kehitaman bayangan laten dalam digital radiografi). Metode pemeriksaan/pengujian dengan teknik radiografi menggunakan ketebalan ganda bayangan tunggal [1].

\section{TEORI}

Prosedur radiografi digital menggunakan Imaging Plate Blue dan pemindai Computed Radiography dengan melihat pengaruh ketebalan filter screen $\mathrm{Pb}$ mengacu pada ASME section $V$ [1] untuk teknik radiografi dan ASTM Reference Radiographs for Heavy walled (51 to $114 \mathrm{~mm}$ ) Steel Castings [2] atau ASTM Reference Radiographs for Steel Castings up to $51 \mathrm{~mm}$ in thickness [3] untuk standar penerimaan hasil radiografi.

Grey value menunjukkan kecerahan piksel. Grey value minimum adalah 0, grey value maksimum bergantung pada kehitaman digitisasi gambar. Untuk gambar 16 bit tingkat kehitaman adalah 65536. Secara teori grey value yang diijinkan untuk radiografi digital adalah antara 6109 sampai 56649 [4].

Screen filter $\mathrm{Pb}$ merupakan material yang bersifat mereduksi atau menyerap energi radiasi foton, dirumuskan sebagai berikut :

$$
D t=\text { Do. Exp (-In2 x t/HVL) }
$$

Dt = Dosis setelah melewati penahan screen filter $\mathrm{Pb}$

Do = Dosis sebelum melewati panahan screen filter $\mathrm{Pb}$

$\mathrm{t}=$ tebal penahan screen filter $\mathrm{Pb}$

$\mathrm{HVL}=$ Nilai tebal paro penahan sreen Filter $\mathrm{Pb}$

Intensitas radiasi yang diterima oleh Imaging plate blue akan berkurang karena penahan screen filter $\mathrm{Pb}$ yang mengakibatkan proses penghitaman Imaging plate blue berkurang.

\section{TATAKERJA (BAHAN DAN METODE)}

Bahan radiografi pada metal adalah sebagai berikut:

1. Benda uji Ignition Coil dengan ketebalan bervariasi.

2. Imaging Plate blue 1 set 
Peralatan yang digunakan adalah Radiografi ini menggunakan metode sebagai berikut :

1. Sumber sinar-X 1 unit

2. Computed Radiography Durr 1 unit

3. $\mathrm{Pb}$ lembaran tebal $3 \mathrm{~mm} 2$ lembar

4. Lead Letter $\mathrm{Pb} 1$ set

5. Longtang 1 set

6. Surveymeter 1 set

7. Rollmeter 1 set

8. Statip pendukung 1 set

9. Filter screen $\mathrm{Pb} 4$ set

ketebalan tunggal bayangan tunggal (single wall single image (SWSI) dengan obyek uji Ignition Coil, Sumber sinar-X Rigaku RF 300 EGM2 dengan tegangan tinggi $130 \mathrm{kV}$ dan arus $5 \mathrm{~mA}$, Film Fuji 100 , Filter screen $\mathrm{Pb}$ dengan 1 tebal $0,125 \mathrm{~mm}$, SFD adalah $1200 \mathrm{~mm}$, waktu paparan 120 detik. Dalam pengujian ini menggunakan langkah-langkah kerja seperti diperlihatkan pada Gambar 1.

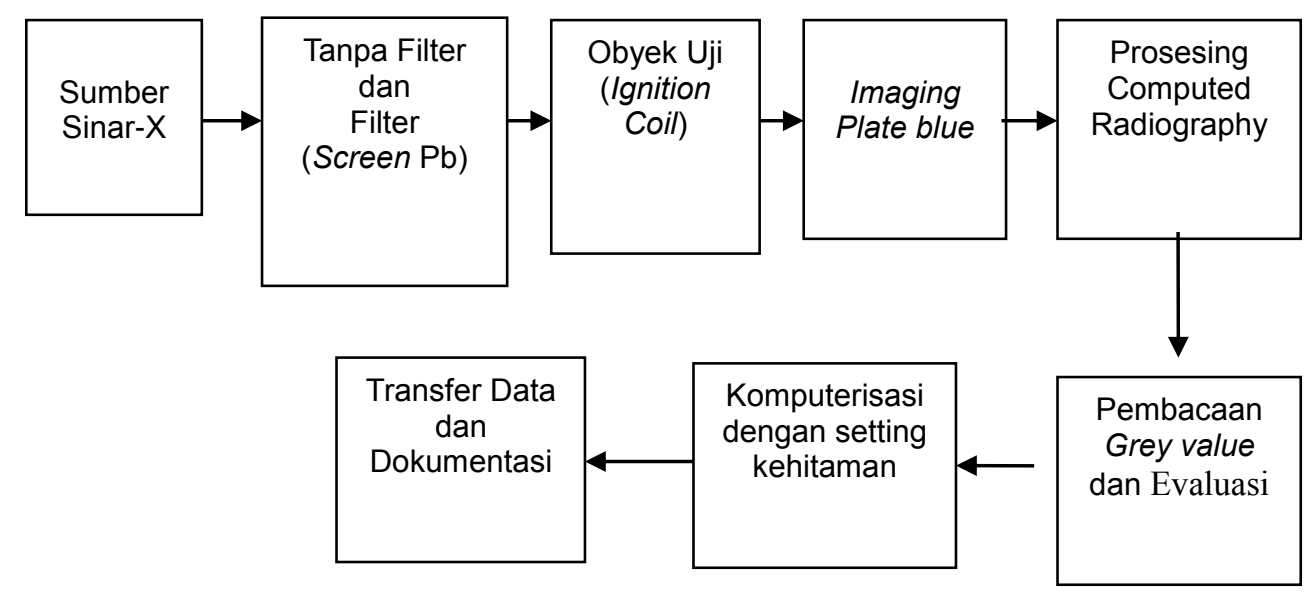

Gambar 1. Langkah-langkah kerja

\section{HASIL DAN PEMBAHASAN}

Pengujian ini menggunakan obyek uji adalah Ignition Coil, mempunyai ketebalan material yang bervariasi. Berdasarkan tebal obyek uji dengan menggunakan kurva paparan sinar- $X$ (Lampiran 1) mendapatkan waktu paparan trial by error adalah 120 detik untuk radiografi dengan jarak tegak lurus antara sumber dan film (Source Film Distance atau SFD) tegak lurus adalah $1200 \mathrm{~mm}$ dan dimensi sumber adalah 2,50 mm. Imaging Plate yang digunakan adalah blue dengan butiran kristal 25 mikron. Pengujian ini mengamati parameter tingkat grey value radiografi akibat dari variabel parameter ketebalan filter screen $\mathrm{Pb}$. Tingkat grey value tanpa filter screen $\mathrm{Pb}$ dan dengan filter screen $\mathrm{Pb}$ diproses melalui evaluasi software Computed Radiography [4], [5], [6], [7].

Hasil pengujian radiografi digital pada Ignition Coil dengan metoda ketebalan ganda bayangan tunggal menghasilkan parameter rerata radiografi grey value 55429,$24 ; \quad 32759,32$; 20616,$99 ; \quad 13122,75 ; \quad 8825,85$ pada ketebalan filter screen $\mathrm{Pb}$ (perisai) 0 ; $0,125 \mathrm{~mm} ; 0,250 \mathrm{~mm} ; 0,375 \mathrm{~mm} ; 0,5 \mathrm{~mm}$ (lihat tabel 1). Rerata radiografi grey value didapat secara otomatis pada waktu memindai Imaging Plate hasil radiografi digital. Semakin tebal filter screen $\mathrm{Pb}$ menghasilkan grey value yang semakin rendah. Optimal grey value 
pada 32759,32 dengan ketebalan filter screen $\mathrm{Pb}$ (perisai) 0,125 $\mathrm{mm}$. Hal tersebut diatas disebabkan reduksi energi sinar-X dengan filter screen $\mathrm{Pb}$ yang berasal dari efek fotolistrik atau efek Compton.

Hasil pemindaian Imaging Plate blue berupa radiografi digital yang memungkinkan untuk proses transfer data digital atau penyimpanan data digital secara komputerisasi. Hasil pemindaian Imaging Plate blue dapat dilihat pada Gambar 2 sampai dengan Gambar 16.

Ignition Coil dengan penembakan sinar- $\mathrm{X}$ tegangan $130 \mathrm{kV}$, arus $5 \mathrm{~mA}$, waktu 120 detik, SFD $1200 \mathrm{~mm}$ tanpa filter screen $\mathrm{Pb}$ sebagai berikut :

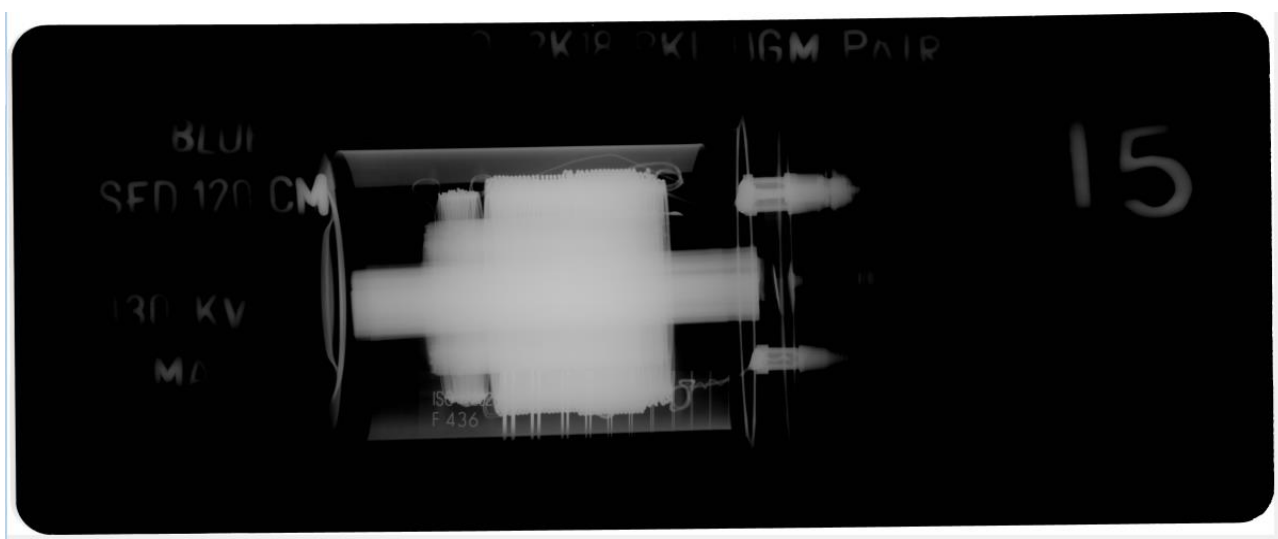

Gambar 2. Hasil Pemindaian IP blue tanpa filter screen $\mathrm{Pb}$.

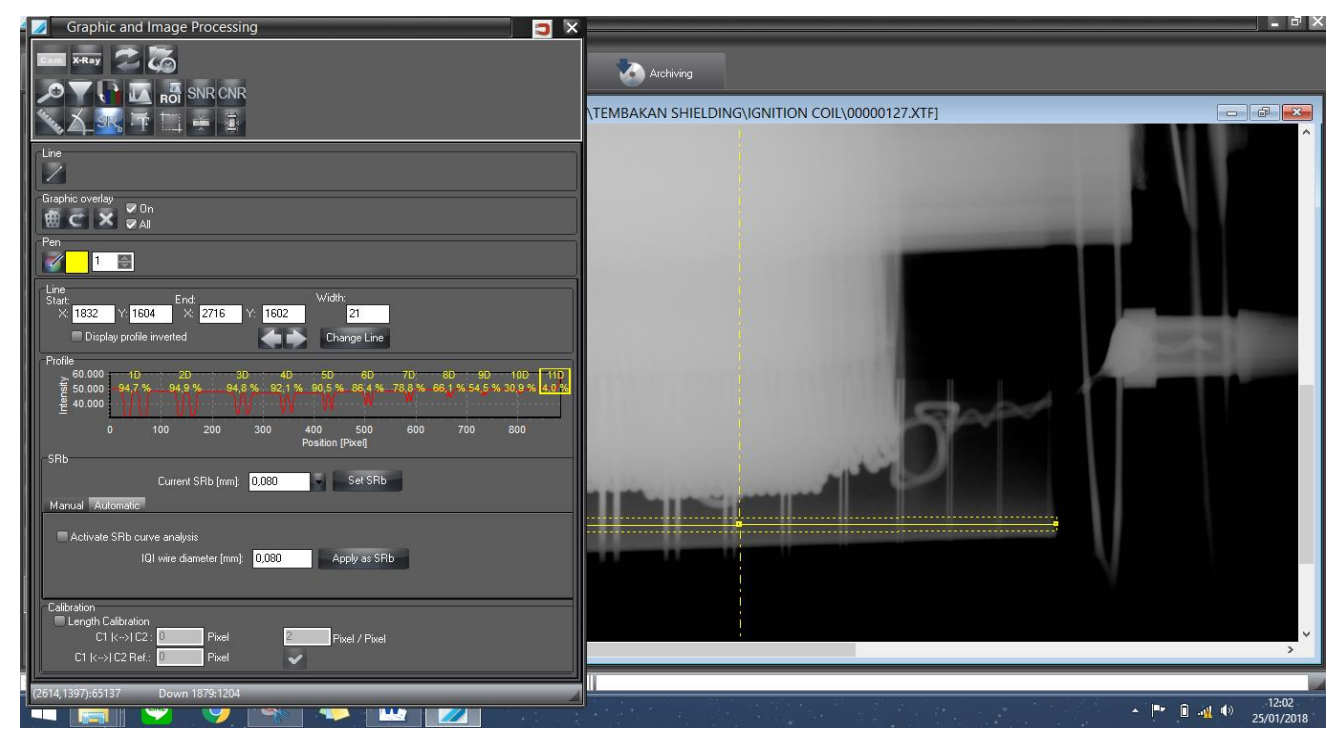

Gambar 3. Terbaca duplex ke $11 \mathrm{SR}_{\mathrm{b}}=0,08 \mathrm{~mm}$ 


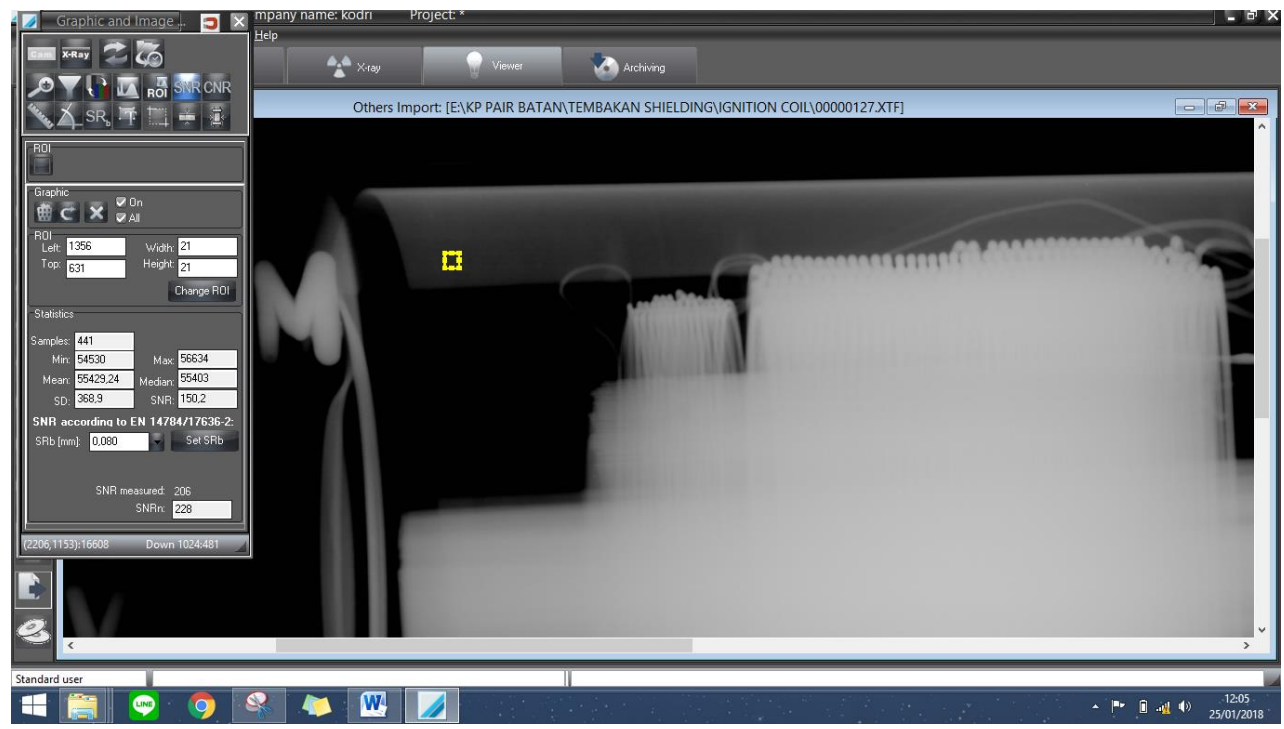

Gambar 4. Terbaca Grey value $=55429,24$.

Tabel 1. Hasil pemindaian IP blue tanpa filter screen $\mathrm{Pb}$

Ignition Coil dengan penembakan sinar- $\mathrm{X}$ tegangan $130 \mathrm{kV}$, arus $5 \mathrm{~mA}$, waktu 120

\begin{tabular}{|l|c|c|}
\hline Duplek & SR $_{\mathrm{b}}$ & Grey Value \\
\hline Ke 11 & $0,08 \mathrm{~mm}$ & 55429,24 \\
\hline
\end{tabular}
detik, SFD $1200 \mathrm{~mm}$ dengan filter screen

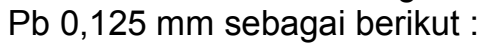

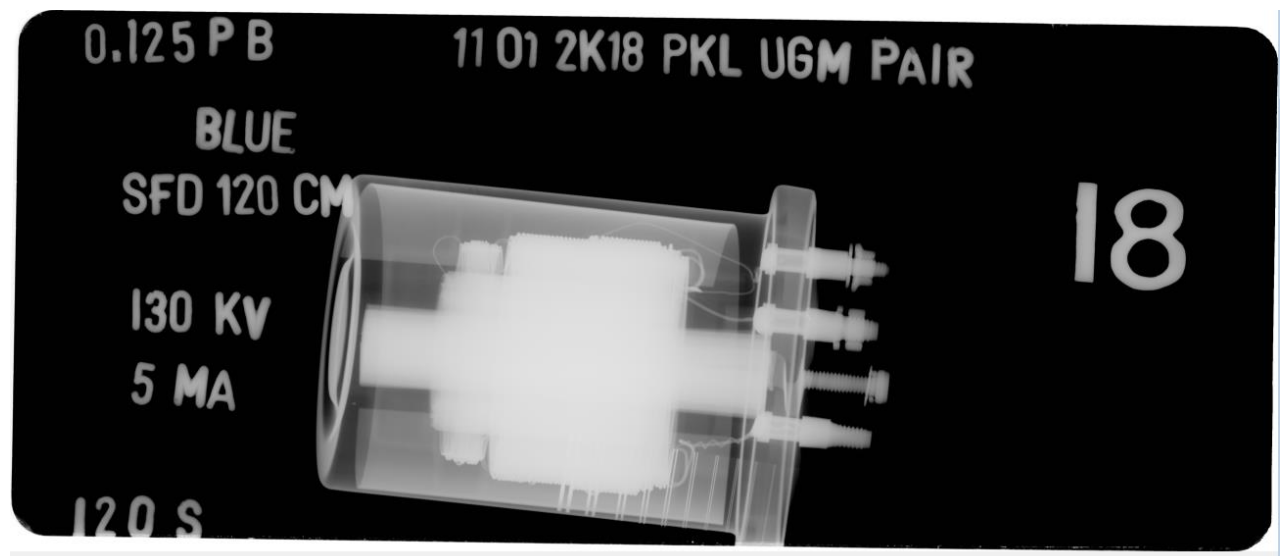

Gambar 5. Hasil Pemindaian IP blue dengan filter screen $\mathrm{Pb} 0,125 \mathrm{~mm}$. 


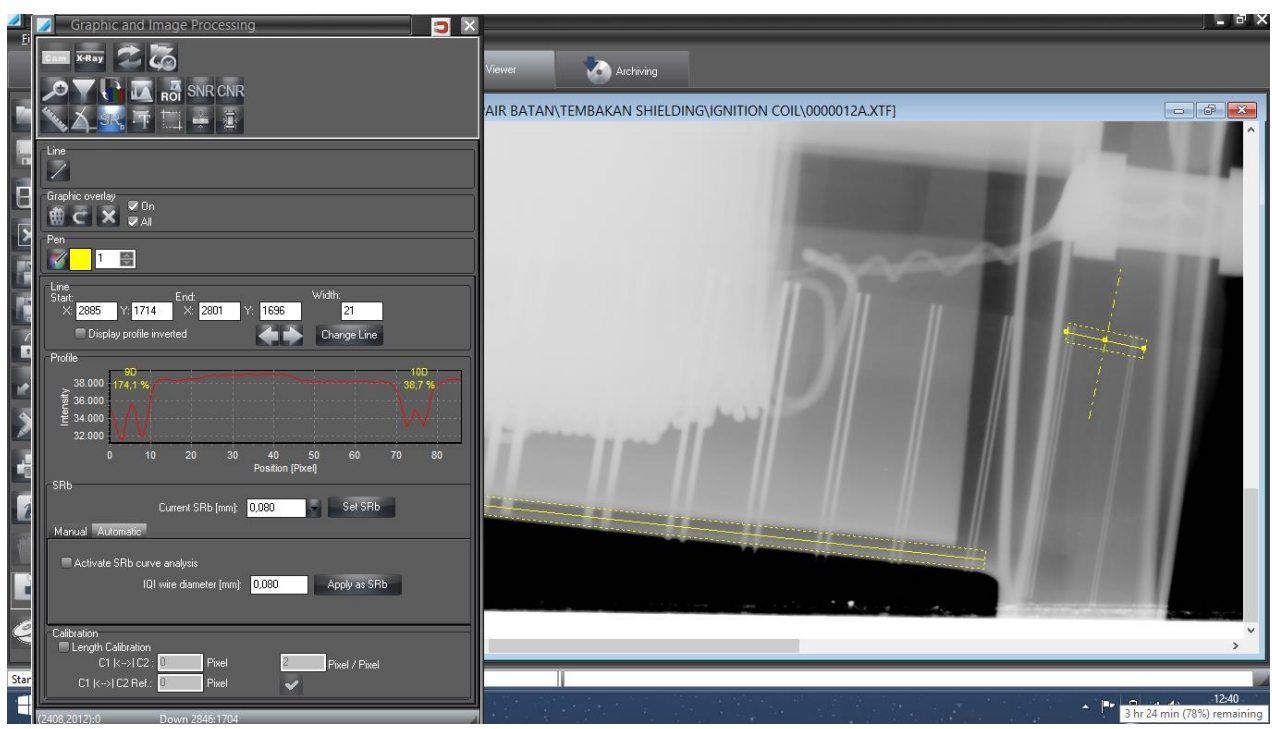

Gambar 6. Duplex yang dapat terbaca hanya sampai duplex ke 11 dengan persentasi intensitas 38,7\% dengan $\mathrm{SR}_{\mathrm{b}}=0,08$

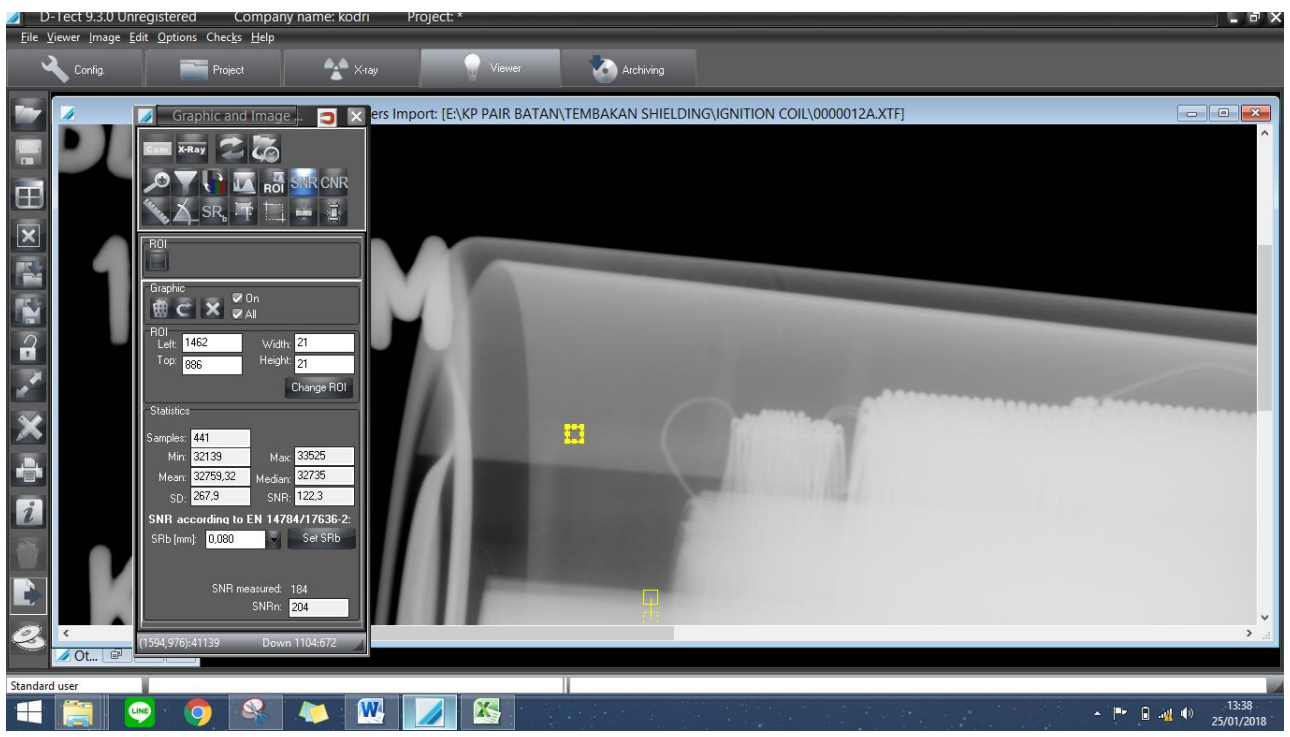

Gambar 7. Terlihat Greyvalue $=32759,32$.

Tabel 2. Hasil pemindaian IP blue dengan filter screen $\mathrm{Pb} 0,125 \mathrm{~mm}$

\begin{tabular}{|c|c|c|}
\hline Duplek & $\mathrm{SR}_{\mathrm{b}}$ & Grey Value \\
\hline Ke 11 & $0,08 \mathrm{~mm}$ & 32759,32 \\
\hline
\end{tabular}

Ignition Coil dengan penembakan sinar- $X$ tegangan $130 \mathrm{kV}$, arus $5 \mathrm{~mA}$, waktu 120 detik, SFD $1200 \mathrm{~mm}$ dengan filter screen $\mathrm{Pb} 0,250 \mathrm{~mm}$ sebagai berikut : 


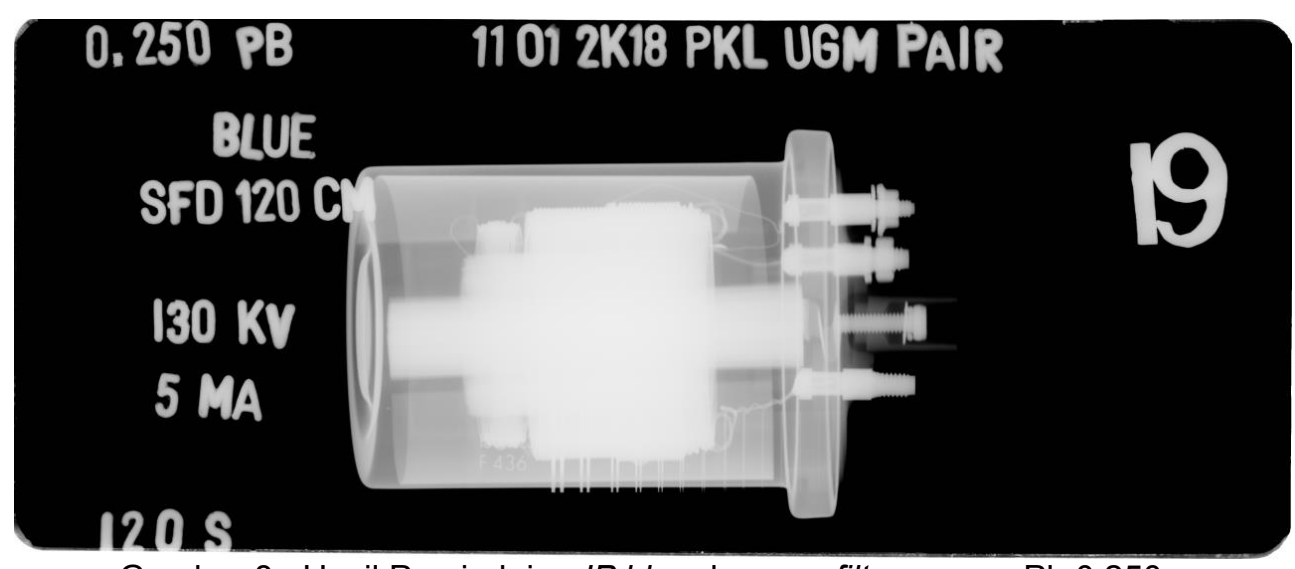

Gambar 8. Hasil Pemindaian IP blue dengan filter screen $\mathrm{Pb} 0,250 \mathrm{~mm}$.

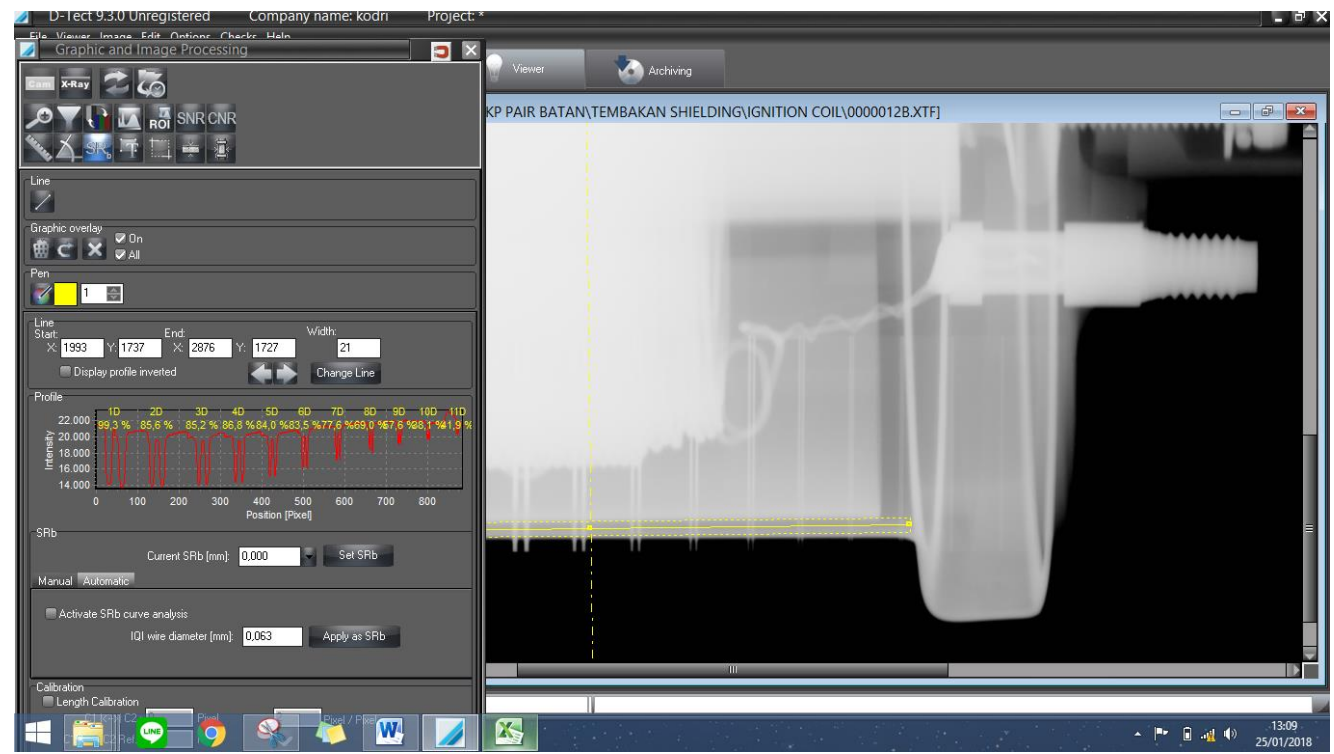

Gambar 9. Duplex yang dapat terbaca hanya sampai duplex ke 11 dengan persentasi intensitas $22,9 \%$ dengan $\mathrm{SR}_{\mathrm{b}}=0,08$ 


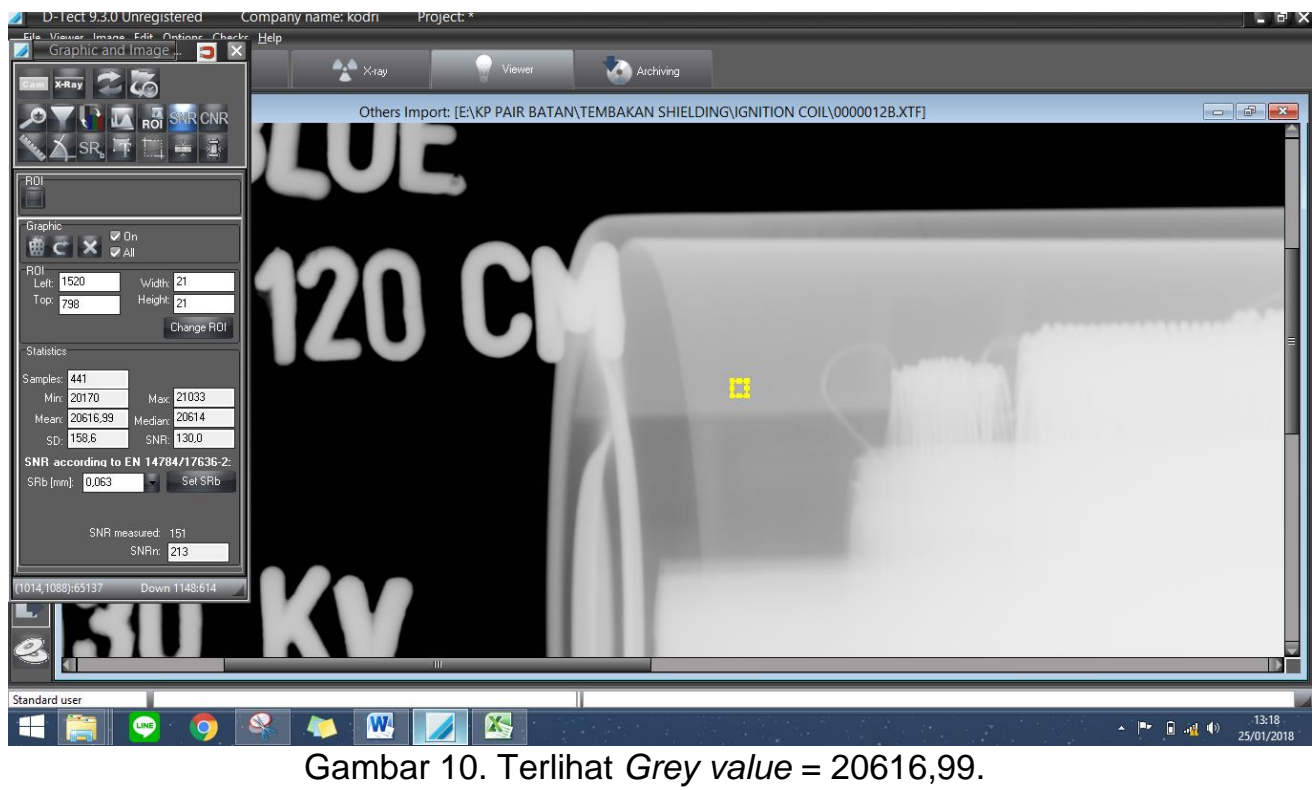

Tabel 3. Hasil pemindaian IP blue dengan filter screen $\mathrm{Pb} 0,250 \mathrm{~mm}$

\begin{tabular}{|l|c|c|}
\hline Duplek & $\mathrm{SR}_{\mathrm{b}}$ & Grey Value \\
\hline Ke 11 & $0,08 \mathrm{~mm}$ & 20616,99 \\
\hline
\end{tabular}

Ignition Coil dengan penembakan sinar- $X$ tegangan $130 \mathrm{kV}$, arus $5 \mathrm{~mA}$, waktu 120 detik, SFD $1200 \mathrm{~mm}$ dengan filter screen $\mathrm{Pb} 0,375 \mathrm{~mm}$ sebagai berikut :

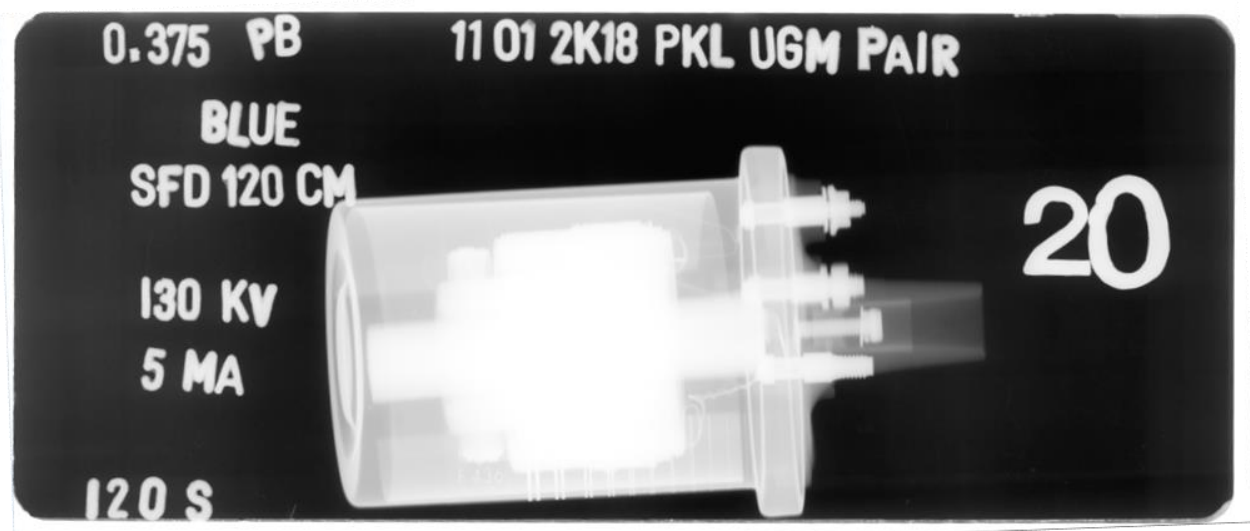

Gambar 11. Hasil Pemindaian IP blue dengan filter screen $\mathrm{Pb} 0,375 \mathrm{~mm}$. 


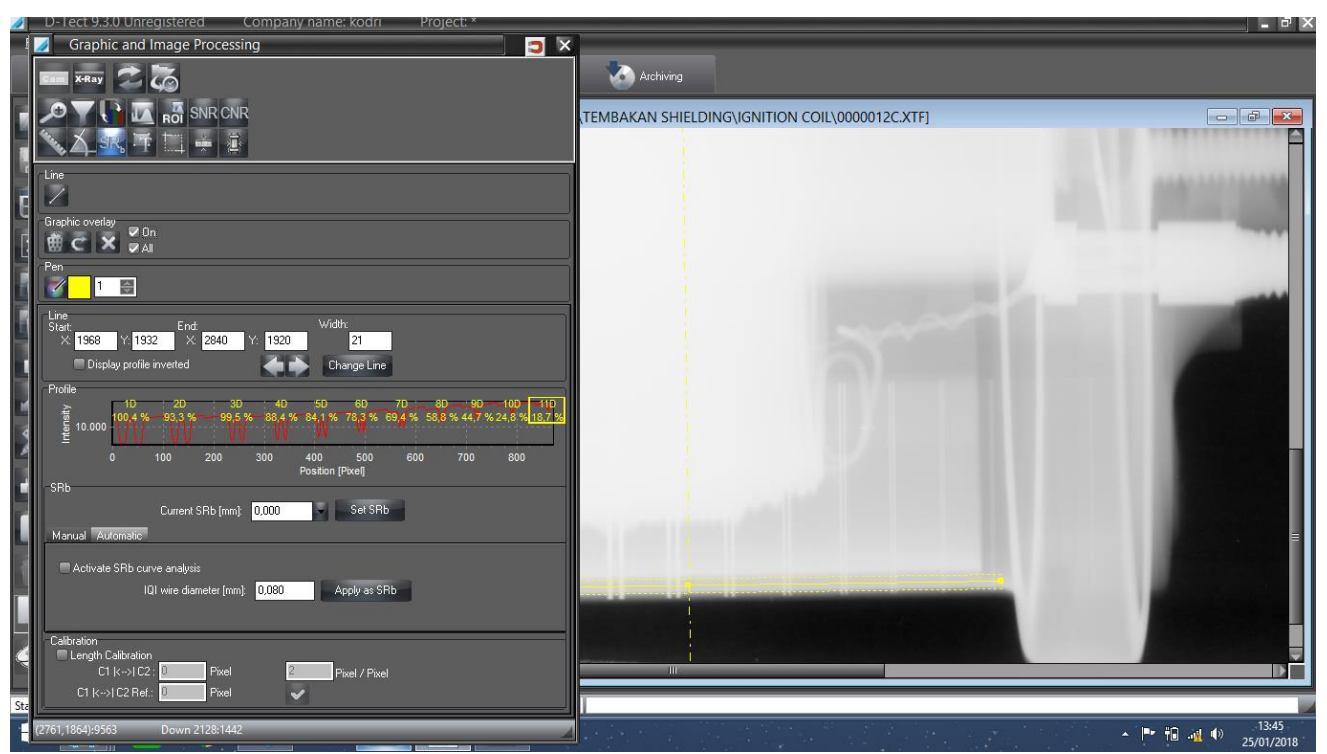

Gambar 12. Ketelitian duplex terkecil pada duplex ke 11 (D11) dengan intensitas sebesar $18,7 \%$ sehingga $\mathrm{SR}_{\mathrm{b}}=0,08 \mathrm{~mm}$.

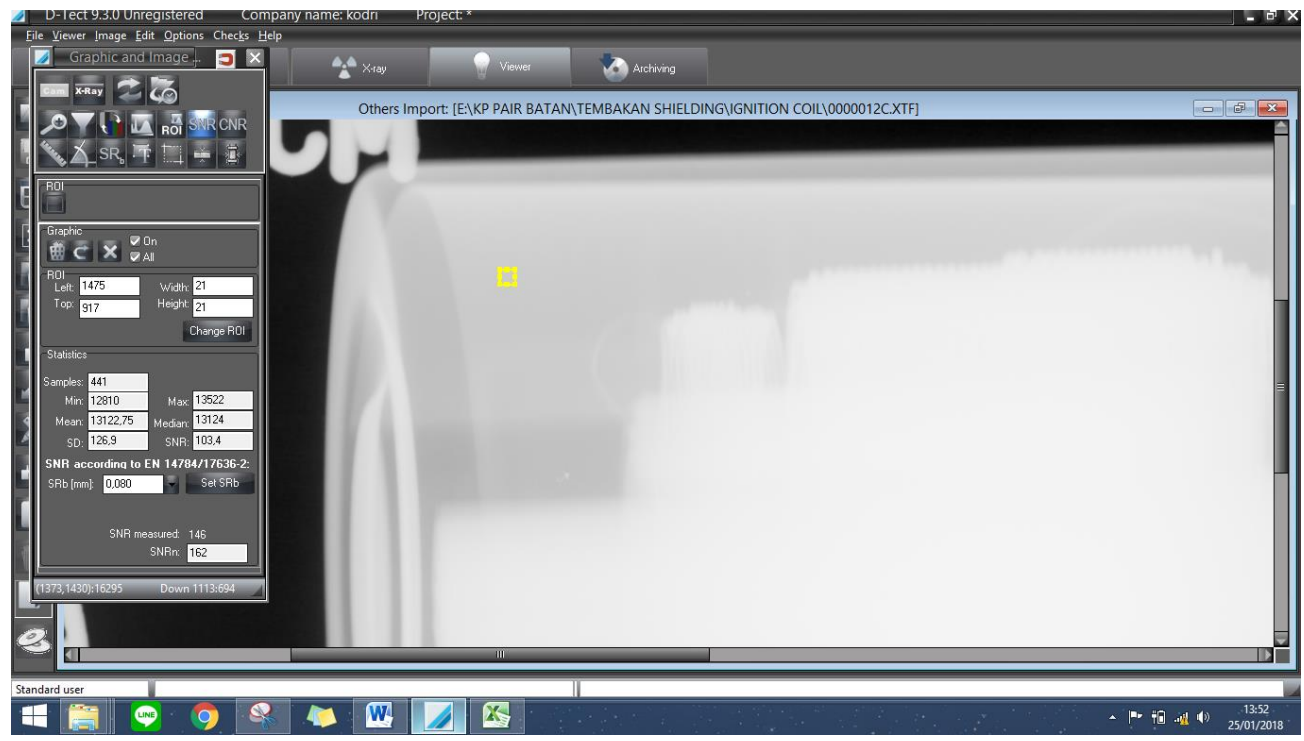

Gambar 13. Terlihat Grey value $=13122,75$

Tabel 4. Hasil pemindaian IP blue dengan filter screen $\mathrm{Pb} 0,375 \mathrm{~mm}$

\begin{tabular}{|l|c|c|}
\hline Duplek & $\mathrm{SR}_{\mathrm{b}}$ & Grey Value \\
\hline Ke 11 & $0,08 \mathrm{~mm}$ & 13122,75 \\
\hline
\end{tabular}

Ignition Coil dengan penembakan sinar- $\mathrm{X}$ tegangan $130 \mathrm{kV}$, arus $5 \mathrm{~mA}$, waktu 120 detik, SFD $1200 \mathrm{~mm}$ dengan filter screen $\mathrm{Pb} 0,500 \mathrm{~mm}$ sebagai berikut : 


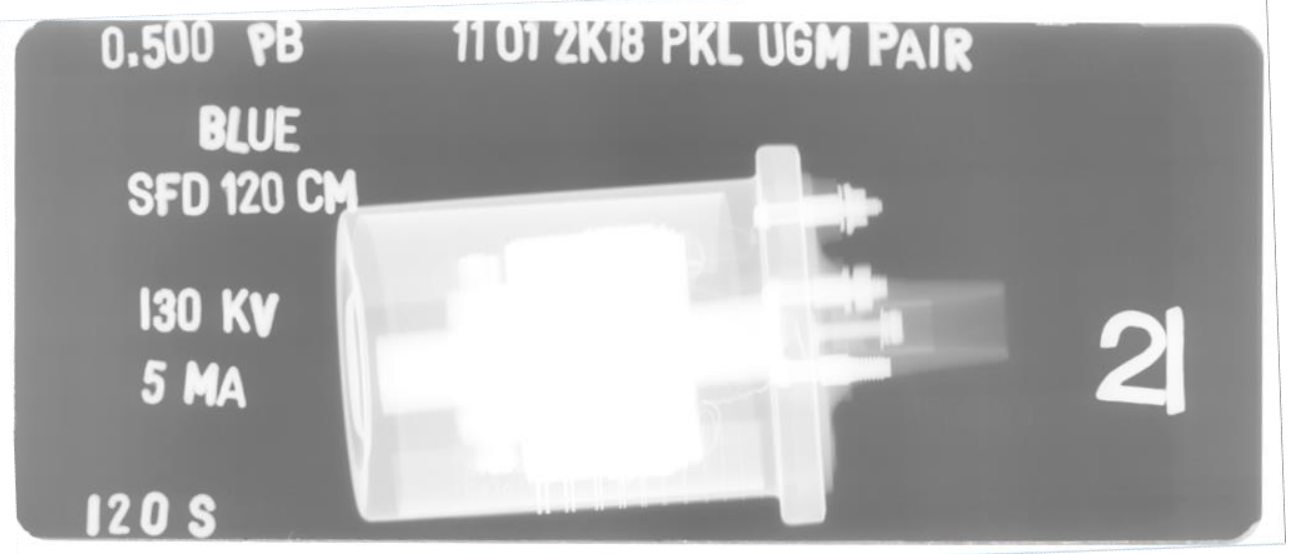

Gambar 14. Hasil Pemindaian IP blue dengan filter screen $\mathrm{Pb} 0,500 \mathrm{~mm}$.

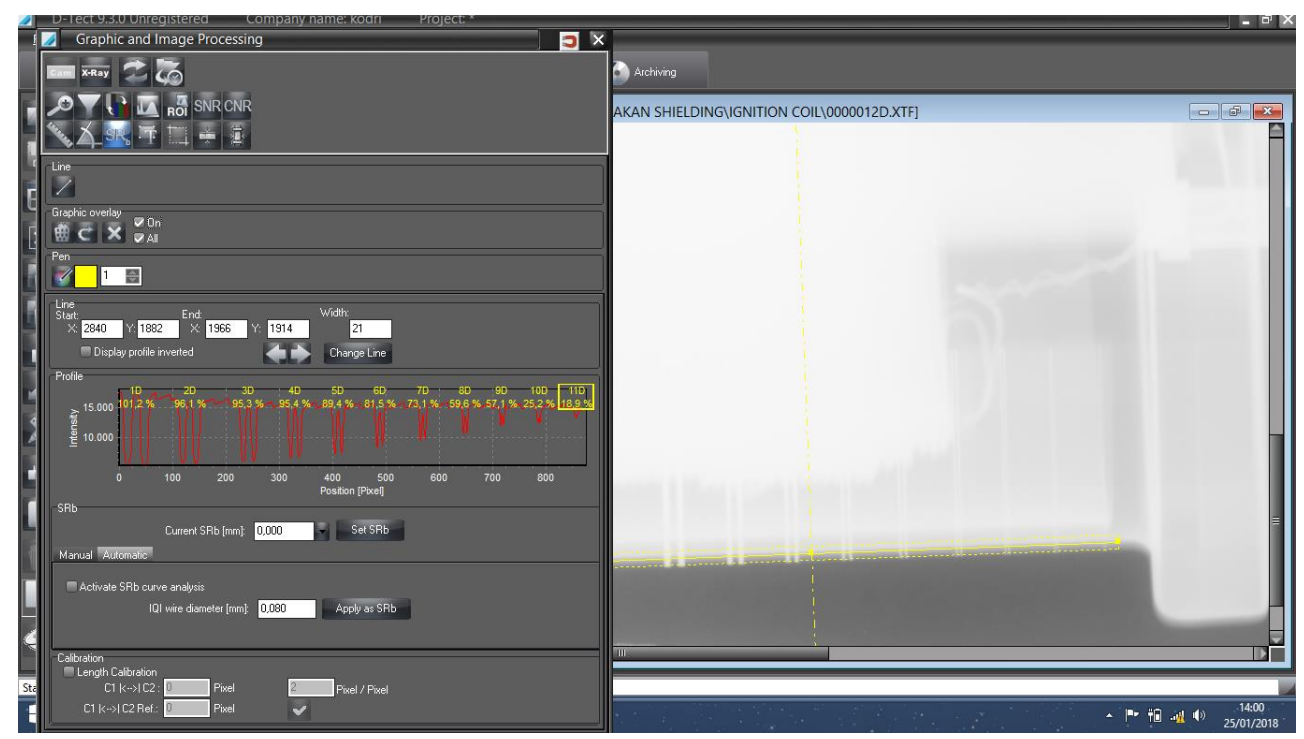

Gambar 15. Ketelitian duplex terkecil pada duplex ke 11 (D11) dengan intensitas sebesar $18,9 \% \mathrm{SR}_{\mathrm{b}}=0,08 \mathrm{~mm}$. 


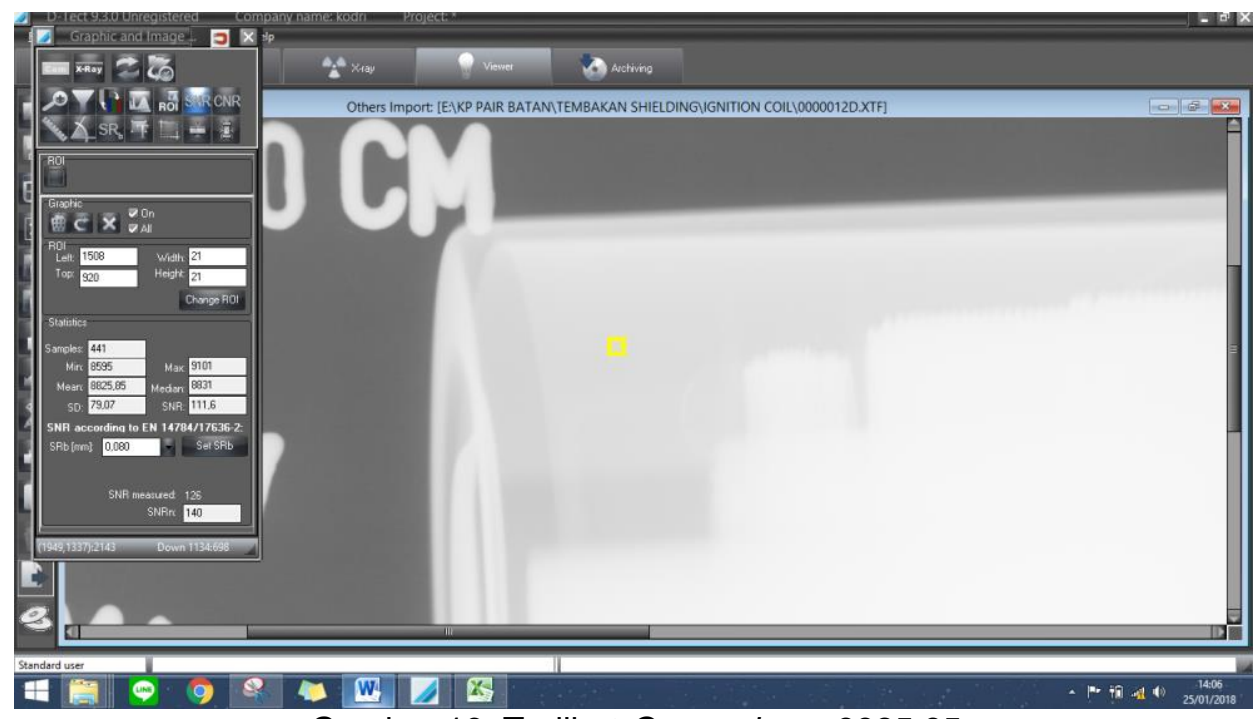

Gambar 16. Terlihat Grey value = 8825,85.

Tabel 5. Hasil pemindaian IP blue dengan filter screen $\mathrm{Pb} 0,500 \mathrm{~mm}$

\begin{tabular}{|l|c|c|}
\hline Duplek & $\mathrm{SR}_{\mathrm{b}}$ & Grey Value \\
\hline Ke 11 & $0,08 \mathrm{~mm}$ & 8825,85 \\
\hline
\end{tabular}

Data tersebut diatas terlihat bahwa Grey value akan terpengaruh oleh tingkat ketebalan filter screen $\mathrm{Pb}$, nilai Grey value menurun jika filter screen $\mathrm{Pb}$ semakin tebal. $\mathrm{SR}_{\mathrm{b}}$ (tingkat sensitivitas mendeteksi kawat terkecil pada duplex) cenderung tidak terpengaruh oleh tingkat ketebalan filter screen $\mathrm{Pb}$.
Tabel 1. Hasil kualitas gambar pada Ignition Coil dengan variasi tebal filter screen $\mathrm{Pb}$.

\begin{tabular}{|c|c|c|}
\hline \multicolumn{3}{|c|}{ Sampel Uji INJECTION COIL } \\
\hline No. & $\begin{array}{c}\text { Tebal filter } \\
\text { screen }(\mathrm{mm})\end{array}$ & Grey value \\
\hline 1 & 0 & 55429,24 \\
2 & 0,125 & 32759,32 \\
3 & 0,250 & 20616,99 \\
4 & 0,375 & 13122,75 \\
5 & 0,500 & 8825,85 \\
\hline
\end{tabular}




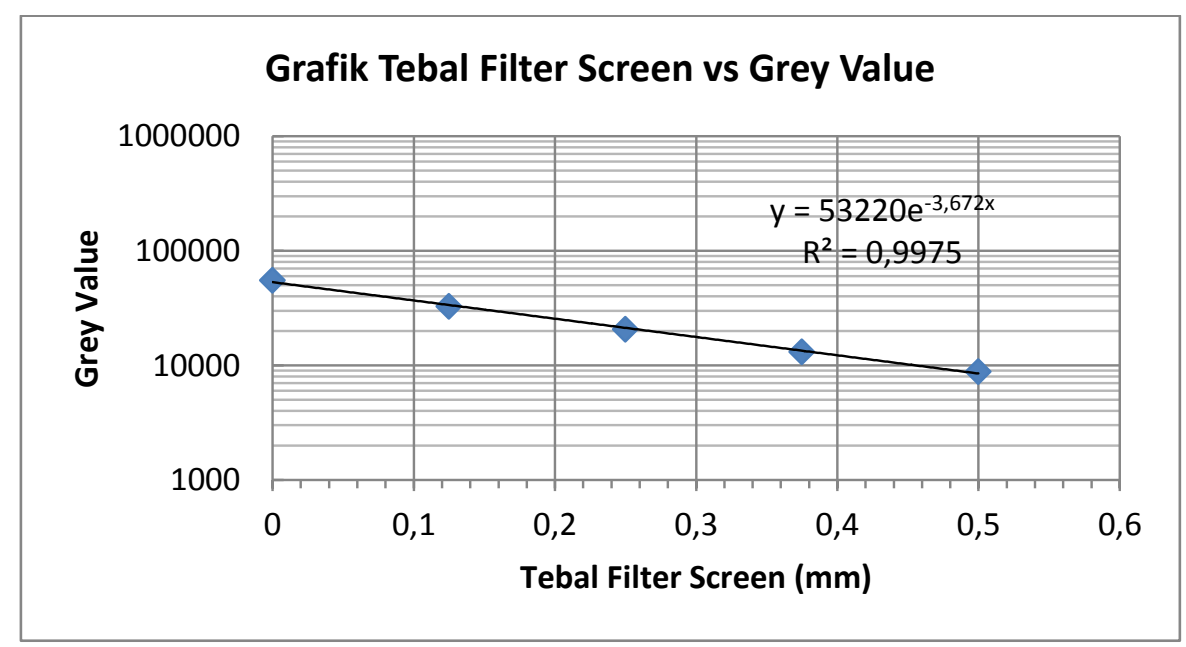

Grafik 1. Hubungan tebal filter Screen dan Grey value.

Berdasarkan data Tabel 1 tersebut diatas, dapat dilihat bahwa filter Screen $\mathrm{Pb}$ mempengaruhi tingkat kehitaman (grey value) radiografi. Hal ini disebabkan oleh energi sinar- $X$ yang mengalami pengurangan (attenuasi) sebelum mengenai benda uji (Ignition Coil) sehingga pembentukan bayangan laten Imaging Plate radiografi juga mengalami pengurangan energi (attenuasi), akibatnya grey value akan tereduksi. Berdasarkan Gambar 2 sampai dengan Gambar 16 dan data tersebut diatas, maka terlihat jelas Grey value optimal pada 32759,32 dengan ketebalan filter screen $\mathrm{Pb}$ pada 0,125 $\mathrm{mm}$.

\section{KESIMPULAN}

Dengan adanya penggunaan filter screen $\mathrm{Pb}$ akan menghasilkan sinar- $\mathrm{X}$ yang mengalami attenuasi, hal ini mengakibatkan reduksi grey value pada Computed Radiography. Besarnya reduksi grey value Computed Radiography bergantung pada ketebalan filter screen $\mathrm{Pb}$. Grey value didapat minimal 8825,85 dan maksimal 55429,24 sudah sesuai dengan yang dijinkan dan optimalnya grey value adalah 32759,32 .

\section{UCAPAN TERIMAKASIH}

Penulis mengucapkan terima kasih kepada rekan-rekan Kelompok Investigasi Tak Merusak dan Diagnosis di Pusat Aplikasi Isotop dan Radiasi yang telah membantu terbentuknya tulisan ini.

\section{DAFTAR PUSTAKA}

1. ASME, ASME section $V$, article 2 Radiographic Examination, New York, (2013).

2. ASTM, ASTM Reference Radiographs for Heavy walled (51 to $114 \mathrm{~mm}$ ) Steel Castings, Philadelphia (1998).

3. ASTM, ASTM Reference Radiographs for Steel Castings up to $51 \mathrm{~mm}$ in thickness, Philadelphia (1998).

4. IAEA, IAEA/RCA Regional Training Course on Digital Industrial Radiology and Computed Tomography Applications in Industry, Kajang, Malaysia, 2-6 November (2009). 
5. IAEA, IAEA/RCA Regional Training Course on the Use of Isee and aRTist Software fo Digital Industrial Radiography (DIR) Image Analysis and Interpretation, Kajang, Malaysia, 25-29 July (2011).

6. PUSDIKLAT BATAN, Radiografi Level II Standar dan Petunjuk Praktikum, Jakarta (2013).
7. DURR NDT, CR 35/HD-CR 35 NDT Plus Instalation and Operating Instructions, Germany, 13 April 2011.

\section{LAMPIRAN}

Lampiran 1. Kurva hubungan paparan sinar-X dan ketebalan metal baja (dari buku manual alat mesin sinar- $X$ Rigaku RF-300EGM2). 
(4) RF-300EGM2 standard exposure chart 1/2

\section{$\mathrm{X}$-ray film}

Intensifying screen

Film-to-X-ray focus distance

Processing

Film density

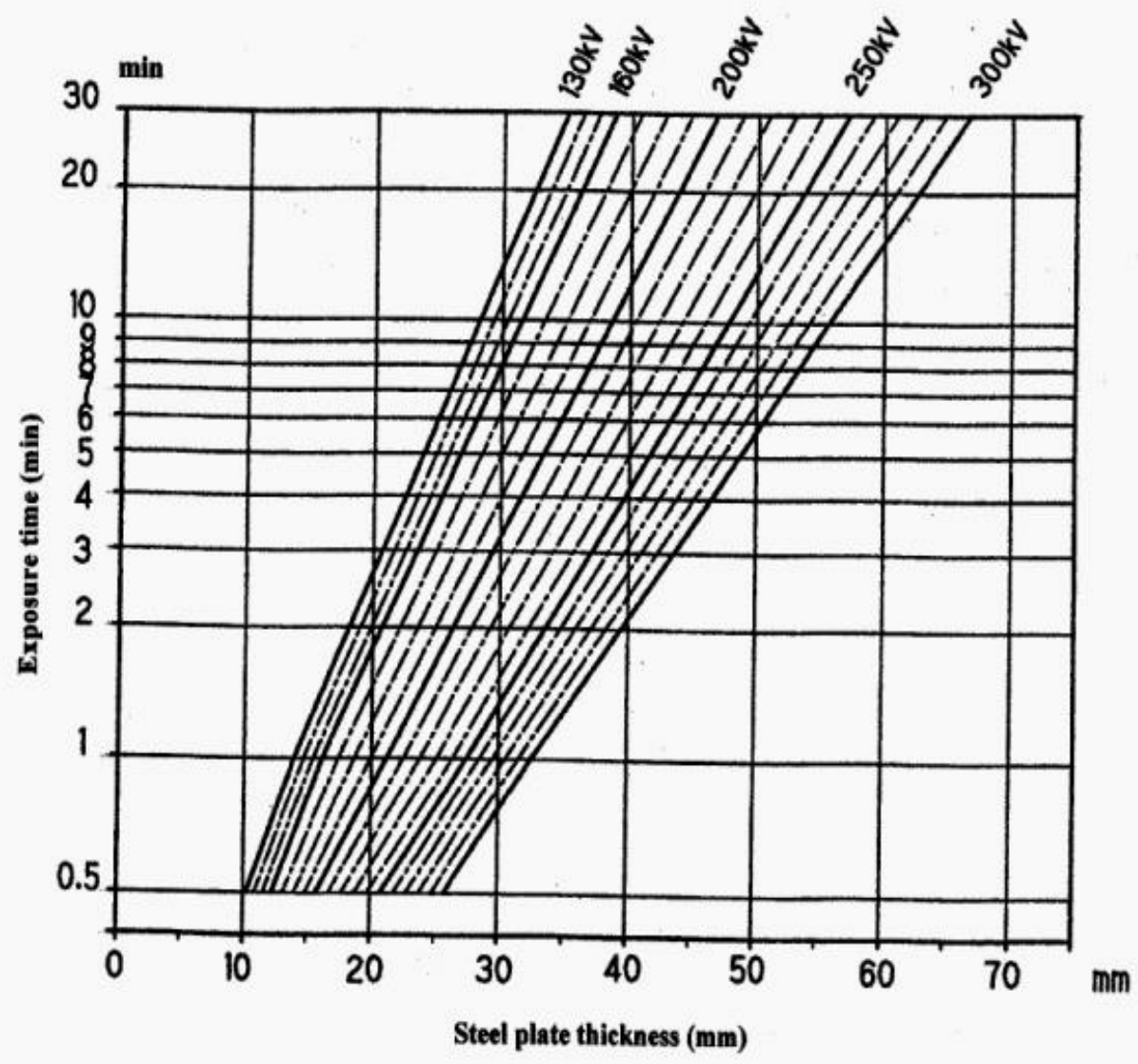

